\title{
Corrigendum: Total synthesis and absolute configuration of avenolide, extracellular factor in Streptomyces avermitilis
}

Miho Uchida, Satoshi Takamatsu, Shiho Arima, Kiyoko T Miyamoto, Shigeru Kitani, Takuya Nihira, Haruo Ikeda and Tohru Nagamitsu

The Journal of Antibiotics (2018) 71, 348; doi:10.1038/ja.2017.148

Correction to: The Journal of Antibiotics (2011) 64, 781-787; doi:10.1038/ja.2011.90

The authors of the above article noted an error in publication of this paper. In the experimental section, present on page 787, the optical rotation of $(4 S, 10 R)$-avenolide $(\mathbf{1})$ is incorrect. The corrected value is $[\alpha]^{23}{ }_{\mathrm{D}}=+29.82\left(c=1.0, \mathrm{CHCl}_{3}\right),[\alpha]^{23}{ }_{\mathrm{D}}=+52.63(c=1.0, \mathrm{MeOH})$. Therefore, this description should be ' $[\alpha]^{23}{ }_{\mathrm{D}}=+29.82 \quad(c=1.0$, $\left.\mathrm{CHCl}_{3}\right), \quad[\alpha]^{23}{ }_{\mathrm{D}}=+52.63(c=1.0, \mathrm{MeOH}) ; \mathrm{IR}(\mathrm{KBr}) 3480,2929$, 2858, 1746, 1710, $1459 \mathrm{~cm}^{-1}$;' 